\title{
Visualising open communities. Guidelines from three case studies
}

\author{
Massimo Menichinelli ${ }^{1}$, Giovanni Profeta ${ }^{2}$ and Serena Cangiano ${ }^{3}$ \\ ${ }^{1}$ IAAC, Fab City Research Lab, Pujades 10208005 Barcelona, Spain \\ massimo@fablabbcn.org \\ ${ }^{2}$ University of Applied Sciences and Arts of Southern Switzerland SUPSI, Department for \\ Environment Constructions and Design, Campus Trevano via Trevano 6952 Canobbio, \\ Switzerland \\ giovanni.profeta@supsi.ch \\ ${ }^{3}$ University of Applied Sciences and Arts of Southern Switzerland SUPSI, Department for \\ Environment Constructions and Design, Campus Trevano via Trevano 6952 Canobbio, \\ Switzerland \\ serena.cangiano@supsi.ch
}

\begin{abstract}
One of the most interesting and promising phenomena of the last years is the emergence of social innovation initiatives, a loose and world-wide movement of people, projects and organisations that are addressing social challenges in fields like healthcare, education, employment, democratic participation, migration and the environment. We especially consider to be very promising those initiatives that are based around communities that adopts digital platforms, develop digital solutions and are open in their processes and results. The importance of online open communities in developing and scaling social innovations could then lead to an improved and broader understanding of the dynamics of social innovations and online platforms. The article aims at improving the knowledge about the use of graphical visualisations for understanding open communities, which data sources and formats are available and which ones are missing for this task, which are the main design requirements and strategies for this task, and which are the common elements in existing ongoing experiences in visualising open communities.
\end{abstract}

Keywords: Open community / Digital platforms / Data visualisation

\section{Introduction}

One of the most interesting and promising phenomena of the last years is the emergence of social innovation initiatives, a loose and world-wide movement of people, projects and organisations that are addressing social challenges in fields like healthcare, education, employment, democratic participation, migration and the environment. These initiatives have been developed with multiple approaches, 
structures, goals and cultures rather than a one-size-fits-all modality. We especially consider to be very promising those initiatives that are based around communities that adopts digital platforms, develop digital solutions and are open in their processes and results. The topics of social innovation and of citizens' participation in processes have been increasingly relevant in the design research and practice in the last years, which has also partially shifted its focus from artifacts to territories, from companies to platforms and ecosystems, from single users to local and online communities, from isolated projects to whole complex systems. Digital social innovation initiatives are very interesting in these directions, and the analysis and visualisation of its open communities is a potential strategy for improving our understanding of them and of the visualisation of complex social systems with a research through design approach.

The importance of online open communities in developing and scaling social innovations render their understanding relevant not just related to the dynamics of specific cases, but also more generically for improving the understanding of the dynamics of social innovations and online platforms. The article aims at improving the knowledge about the use of visualisations for understanding open communities with the research question: which are the main design requirements, common elements and strategies for this task emerging from ongoing experiences? We explored three case studies and we identified key guidelines and limitations for visualising the geographic distribution, history and social dynamics of open communities.

\section{Case Studies}

We analysed three case studies in order to propose guidelines and requirements for the design of visualisations systems of open communities: 2.1) Maker initiatives and their impact, 2.2 ) the Wikipedia community, 2.3) digital social innovations.

\subsection{Fab City Dashboard}

The Maker Movement [1] is a global community interested in designing, making, repairing physical objects with digital fabrication tools in distributed laboratories like Fab Labs and Makerspaces [2]. Its impact is however rarely measured, the MAKE-IT ${ }^{1}$ project investigated several Social Impact Assessment methods for this [3] and, with this case, the potential of platforms for measuring this impact over city resilience with the the Fab City perspective [4]. The Fab City Dashboard ${ }^{2}$ is a web-based prototype developed in a 9-days hackathon at Medialab Prado, Madrid, during

\footnotetext{
${ }^{1}$ http://make-it.io/

${ }^{2}$ http://dashboard.fab.city/
} 
Visualizar' $16^{3}$. It lets user explore the resilience of cities, regions and countries based on wellbeing indexes from OECD $[5,6]$, and has a simplified simulation of the impact of a Maker project over them. The limited datasets available rendered this only a research-through-design exploration of the impact of Makers, providing the space for reflecting about a potential model.

\section{Barcelona}

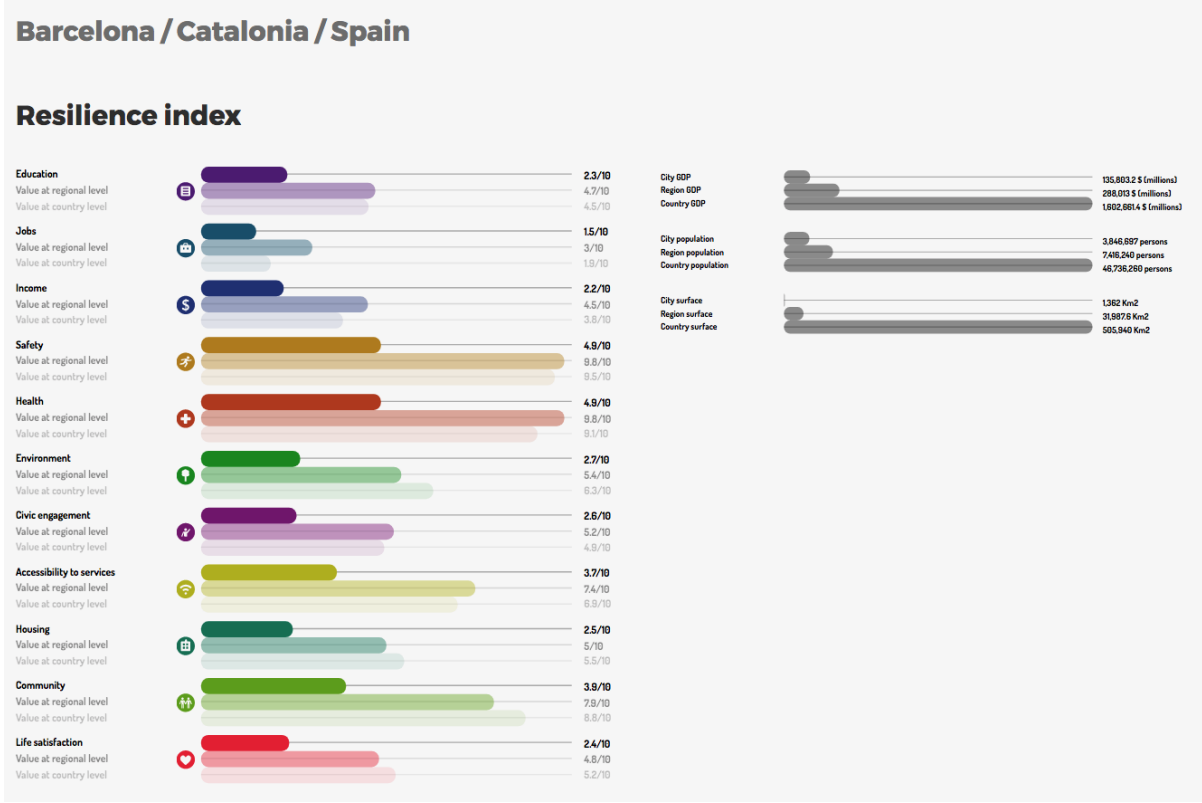

Fig. 1. A screenshot of the Fab City Dashboard showing resilience as wellbeing of cities, regions and countries.

\footnotetext{
${ }^{3}$ https://www.medialab-prado.es/en/news/visualizar16-call-projects
} 




Fig. 2. A screenshot of the Fab City Dashboard simulating the impact of a Maker project over resilience of cities, regions and countries.

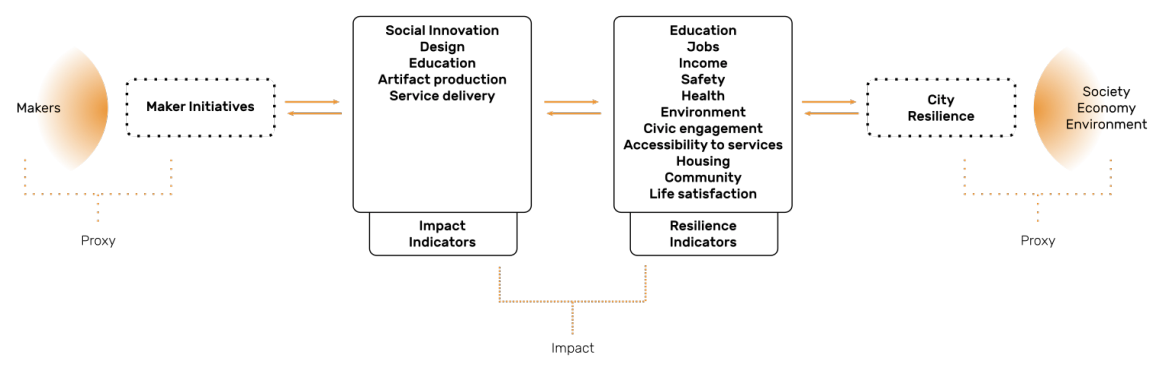

Fig. 3. A conceptual model for understanding the impact of Maker projects over resilience of cities, regions and countries, elaborated from the Fab City Dashboard prototype. 


\subsection{Wikipedia}

The Wikipedia community consists of more than one hundred thousand active users (wikipedians). The Wikipedia Primary School research project ${ }^{4}$ [7] was developed by the University of Applied Sciences and Arts of Southern Switzerland and by the University of Cape Town. The project aims in developing and evaluating a system to assess Wikipedia articles for primary education through the use of multiple strategies (edit-a-thons, review by domain experts etc.) and seeks to involve a wide network of wikipedians and scholars in their production. The focus was on the primary school in South Africa.

The main goals of the visualisation ${ }^{5}$ are: understanding the status of the articles (in quantitative terms) and to evaluate the impact of the strategies. The visualizations take into consideration multiple parameters, such as: connections between articles, user edits and integration of further resources (references, notes and images etc.).

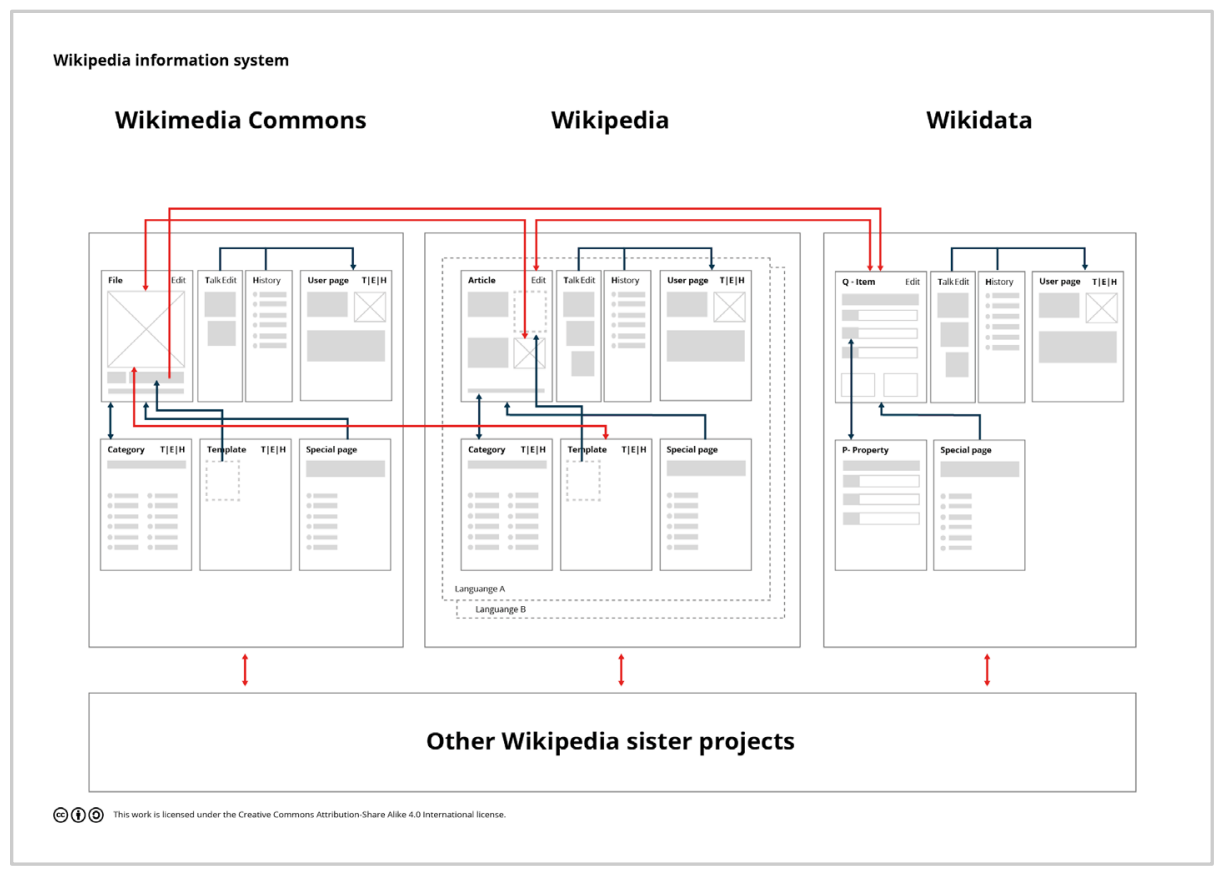

Fig. 4. Wikipedia information system. Laboratorio cultura visiva SUPSI. Lugano.

\footnotetext{
${ }^{4}$ https://meta.wikimedia.org/wiki/Wikipedia_Primary_School

${ }^{5}$ https://meta.wikimedia.org/wiki/Research:Wikipedia_Primary_School_SSAJRP_programme/ Evaluation
} 


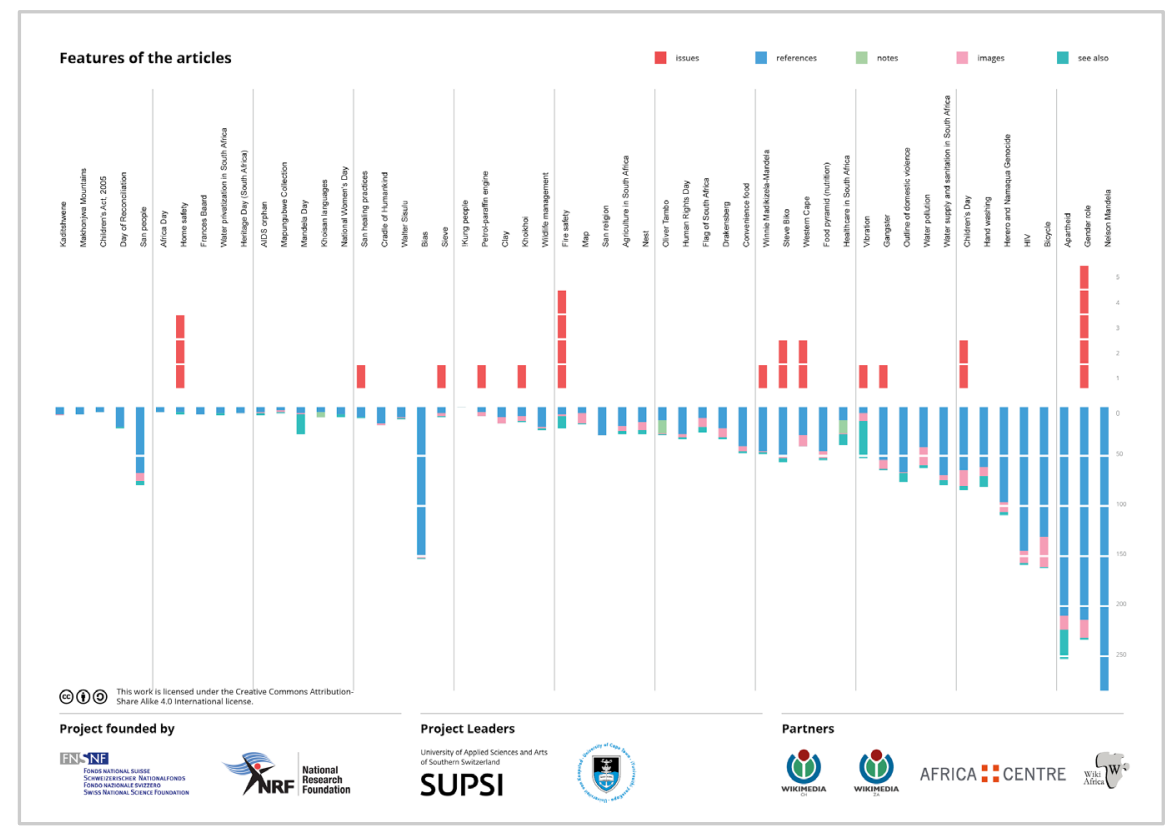

Fig. 5. Visualization of articles' features: issues, images, etc. Laboratorio cultura visiva SUPSI. Lugano.

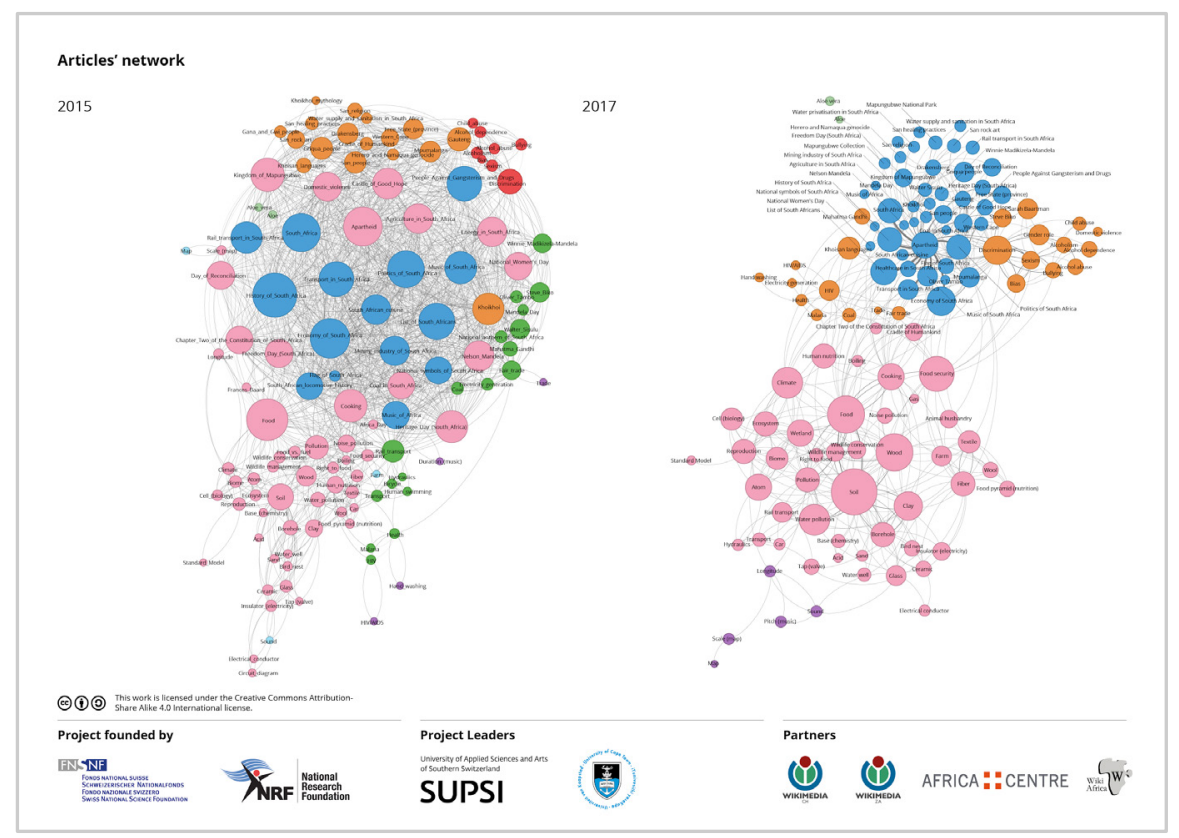

Fig. 6. Comparison of articles' networks. Laboratorio cultura visiva SUPSI. Lugano. 


\subsection{Digital Social Innovation for Europe}

Digitasocial.eu is the web hub of the DSI4EU, an EU funded project that aims to support a growing network of projects and organizations providing a bottom-up approach to tech development. Across Europe digital social innovators are developing inspiring digital solutions to social challenges by using technology, such as the open source software and hardware and open data, crowdsourcing and Internet of Things (IoT). The hub is a network of networks and its interactive visualization reflects the complexity of analysing communities that shares common values but deliver social impact in fields as diverse as healthcare, education, democracy, environment, transport and housing. The visualisation ${ }^{6}$ proposes three views: map, network, projects [8].

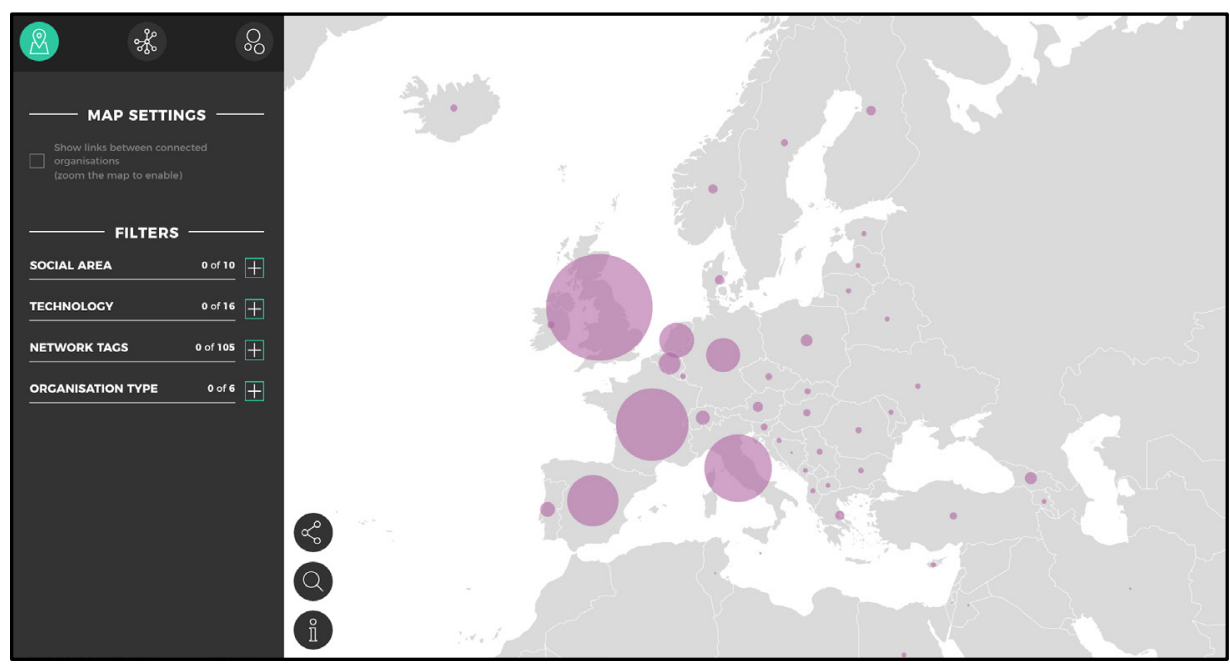

Fig. 7. View from 'Digitalsocial.eu'. DSI4EU Interactive visualization - Map view.

\footnotetext{
${ }^{6}$ https://digitalsocial.eu/viz/
} 


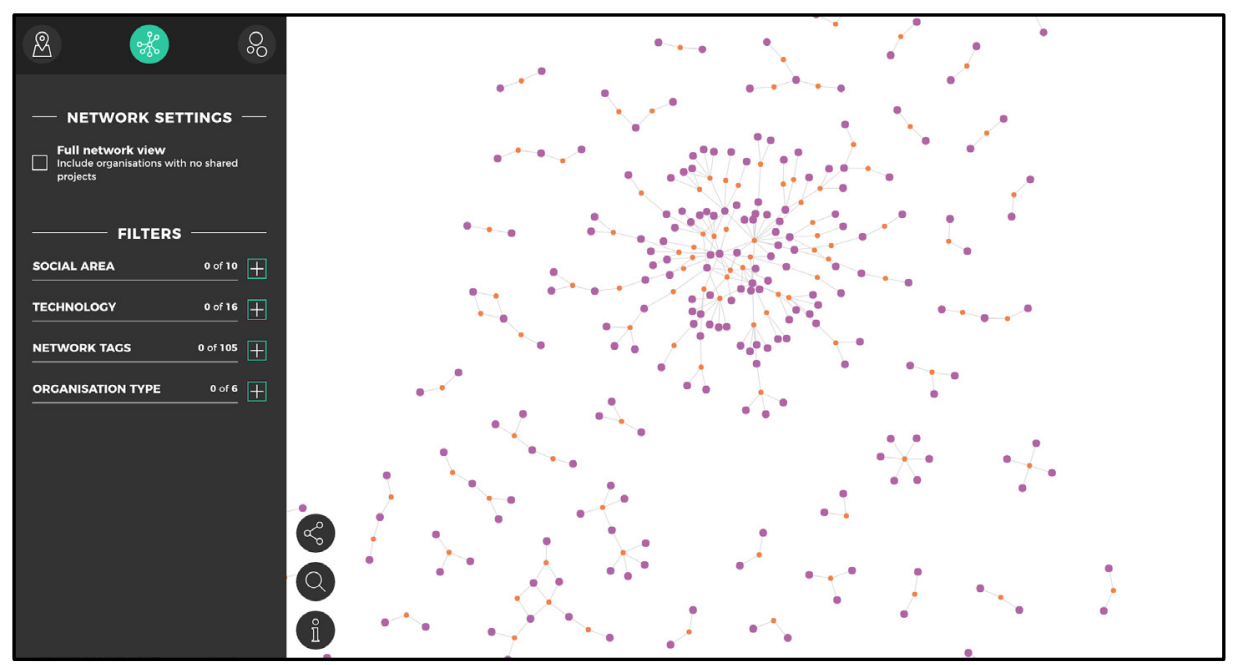

Fig. 8. View from 'Digitalsocial.eu'. DSI4EU Interactive visualization - Network view.

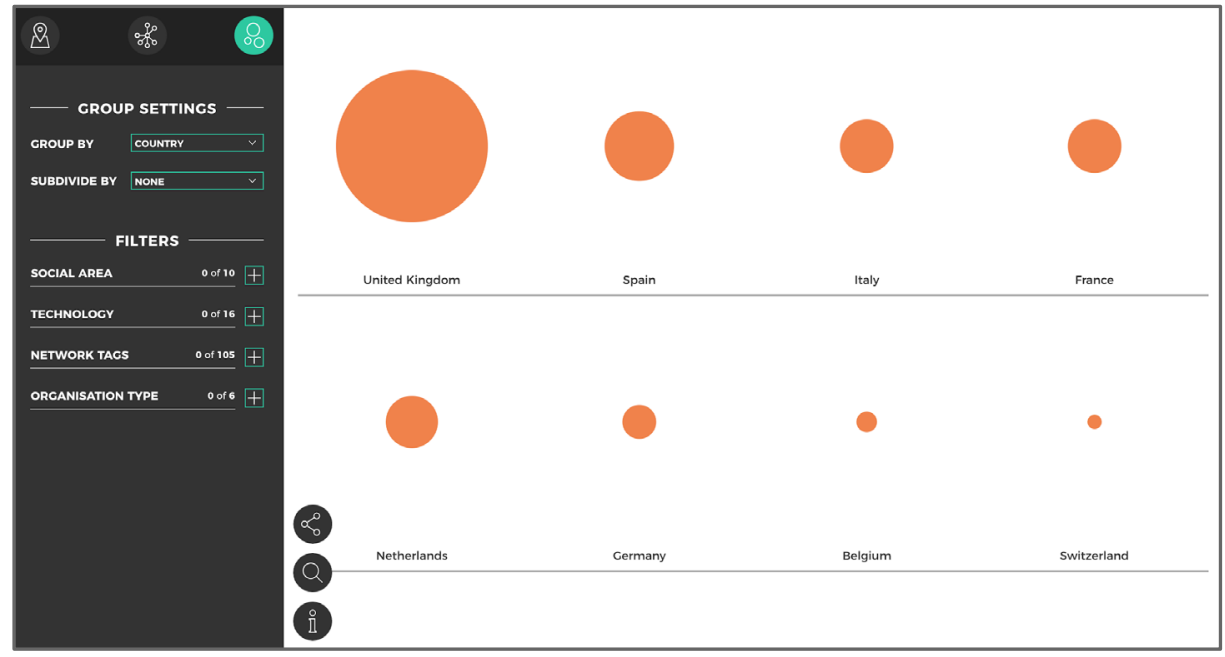

Fig. 9. View from 'Digitalsocial.eu'. DSI4EU Interactive visualization - Project view.

\section{Discussion}

We compared these cases in order to understand their similarities, differences, and common elements in the visualisation of open communities in terms of dimensions 
(geographic, systemic, historical), focus (impact, processes, size and distribution) and strategy (data source, scale, approach) (Table 1).

Table 1. Comparison of the three case studies

\begin{tabular}{|c|c|c|c|}
\hline Case Studies & Fab City Dashboard & Wikipedia & $\begin{array}{l}\text { Digital Social } \\
\text { Innovation }\end{array}$ \\
\hline \multicolumn{4}{|l|}{ Dimensions } \\
\hline $\begin{array}{l}\text { Geographic } \\
\text { (place) }\end{array}$ & $\mathrm{x}$ & & $x$ \\
\hline $\begin{array}{l}\text { Systemic } \\
\text { (network) }\end{array}$ & WIP & $x$ & $x$ \\
\hline Historical (time) & & $\mathrm{x}$ & \\
\hline \multicolumn{4}{|l|}{ Focus } \\
\hline Impact & $x$ & & \\
\hline Processes & WIP & $x$ & \\
\hline $\begin{array}{l}\text { Size and } \\
\text { distribution }\end{array}$ & & & $x$ \\
\hline \multicolumn{4}{|l|}{ Strategy } \\
\hline Data source & External, explored & External, analysed & Own \\
\hline Scale & $\begin{array}{c}\text { Global, selected cities and } \\
\text { regions }\end{array}$ & Global, online & Europe \\
\hline Approach & $\begin{array}{l}\text { Research through design, } \\
\text { Exploratory Simulation }\end{array}$ & $\begin{array}{l}\text { Data-driven } \\
\text { analysis }\end{array}$ & $\begin{array}{c}\text { Crowdsourced } \\
\text { mapping }\end{array}$ \\
\hline
\end{tabular}

From the comparison of the three cases we elaborate these preliminary research guidelines for the visualisation of open communities:

- Manage and visualise ambiguity of cases that can be hardly checked in a coherent way since they are distributed.

- Manage and visualise missing or not completely coherent datasets.

- Manage and visualise user participation in providing datasets, and the consequent quality issues.

- Define metrics in collaboration with domain experts.

- Integrate multiple perspectives with different visualisations instead of one single visualisation.

- Develop simple visualisations and models instead of complex ones, but able to evolve in the future.

- Add in-depth textual explanations to main (complex) concepts. 
- Provide a global and comprehensive overview, but ability to focus on individual elements.

- Start with exploratory analysis with available datasets, refine and then test with stakeholders.

- Aim at finding datasets and elaborate models that can compare cases.

\section{Conclusions}

While the enthusiasms in the positive influence of digital technologies on society has been greatly reduced in the past years, the hopes in digital social innovation initiatives are still high especially thanks to their ability to scale up and engage people in their processes. This article proposes the analysis of three case studies of visualisations focusing on community-based digital social innovation initiatives and elaborated few guidelines. However, we consider the research here presented to have certain limitations:

\section{Case 1:}

- Missing datasets regarding cities, regions, and Maker initiatives.

- Rough model of impact, to be improved.

\section{Case 2:}

- Continuous evolution of Wikipedia content and structure.

- Missing worldwide recognised metrics.

Case 3:

- Cannot support the impact of each organisation because the number of projects cannot demonstrate their effectiveness.

- Cannot compare amongst the organisations and projects.

Considering these limitations, we suggest these directions for future research:

\section{Case 1:}

- Develop a model of impact of Maker initiatives over cities and regions based on easily accessible and scalable datasets, and develop tools accordingly.

- Integrate with analysis and visualisation of processes.

\section{Case 2:}

- Apply the research approach to other countries and education systems.

- Foster the Wikipedia community to adopt visual models to evaluate articles.

Case 3:

- Visualise qualitative data regarding the sustainable scalability of the projects. 
Generally, we suggest that future research should focus on a coherent framework for understanding and visualising open communities by integrating these three perspectives and test it and the cases with stakeholders and domain experts.

\section{Acknowledgements}

This research received funding from:

1. the Horizon 2020 Programme of the European Union within the MAKE-IT project under grant agreement $n^{\circ} 688241$.

2. the Swiss National Science Foundation, the National Research Foundation of South Africa, in partnership with Wikimedia $\mathrm{CH}$, Wikimedia $\mathrm{ZH}$, Africa Centre and Wiki Africa.

3. the Horizon 2020 Programme of the European Union within the DSI4EU project under grant agreement $n^{\circ} 688192$.

This publication reflects only the authors' views and the European Union is not liable for any use that may be made of the information contained therein.

\section{References}

[1] Anderson, C. (2012). Makers: The New Industrial Revolution. New York: Crown Business.

[2] Menichinelli, M. (2016). Mapping the structure of the global maker laboratories community through Twitter connections. In C. Levallois, M. Marchand, T. Mata, \& A. Panisson (Eds.), Twitter for Research Handbook 2015 - 2016 (pp. 47-62). Lyon: EMLYON Press. Retrieved from http://dx.doi.org/10.5281/zenodo.44882

[3] Sbeih, J., Pelka, B., Zirngiebl, M., Millard, J., Unterfrauner, E., Langley, D., ... Cuypers, M. (2017). D6.2 Societal Impact Analysis and Sustainability Scenarios (MAKE-IT No. D6.2). Retrieved from http://make-it.io/deliverables/

[4] Diez, T. (2016, June). Fab City Whitepaper. IAAC Bits, 6(4.3). Retrieved from https://issuu.com/iaacbits/docs/6.4.3_white_paper_fab_lab

[5] OECD. (2011). How's Life? Measuring well-being. OECD Publishing. https://doi.org/10.1787/9789264121164-en

[6] OECD. (2014). How's Life in Your Region? Measuring Regional and Local Well-being for Policy Making. OECD Publishing. https://doi.org/10.1787/9789264217416-en

[7] Cangiano, S., Profeta, G., Lurati, M., Elsharbaty, S., Pensa, I.\& Devouard, F. (2017) Community Digest: Using data to visualize Wikipedia knowledge gaps; news in brief. Wikimedia Foundation Blog. Retrieved from: https://blog.wikimedia.org/2017/02/23/digest-data-visualization.

[8] Cangiano, S., Romano, Z., \& Loglio, M. (2017). The growth of digital social innovation in Europe. An Open Design approach to support innovation for the societal good. The Design Journal, 20 (sup1), S3546-S3559. https://doi.org/10.1080/14606925.2017.1352857 